\title{
Performance Analysis of Diesel Engine using Copper Oxide Nano Additive
}

\author{
Sabarish Kumar P, Arthur Jebastine Sunderraj, K. Arun Vasantha Geethan, Harish Praveen, Gilbert
}

\begin{abstract}
This experimental study focuses on investigation of performance and utterance attributes of a normal diesel engine with biodiesel prepared from pongamia. This study aims to reduce the emission of nitrogen oxide by adding an oxidation inhibitor Tert-Butylhydroquinone (TBHQ). The analysis for each sample is to be carried out in compression ignition engine (standard diesel engine). The engine is tested with standard diesel, pongamia methyl ester biodiesel without any additives. Then the analysis is to be carried by adding nano additive copper oxide for about $50 \mathrm{ppm}$ in the above mentioned fuels. From this the best combination is found out and test is again carried out by adding the oxidation inhibitor.
\end{abstract}

Keywords: Pongamia biodiesel, Tert-Butylhydroquinone (TBHQ), copper oxide.

\section{INTRODUCTION}

In the past decades, petroleum based liquid fuels have played a significant role in fulfilling the energy demand as far as automobiles are concerned. Petroleum based liquid fuels are derived from fossil energy sources which are non-renewable in nature which may get depleted in few more decades. These have led researchers to focus on renewable source of energy for reducing the reliance on fossil fuels. Also the petroleum products lead to severe environmental problems such as air pollution and global warming. In that view, biodiesel which is renewable form of energy is derived from vegetable oil or animal fat based oil has drawn a lot of attention among researchers. It is considered to be the better alternative for diesel fuel in standard diesel engine. This is because biodiesel possess almost similar properties as diesel. Also the use of biodiesel does not require a major modification in the engine construction.

Revised Manuscript Received on February 05, 2020.

* Correspondence Author

Sabarish Kumar P*, School of Mechanical Engineering, St.Joseph's Institute of Technology, OMR, Chennai 119.*pskgps@gmail.com

Arthur Jebastine Sunderraj, School of Mechanical Engineering, St.Joseph's Institute of Technology, OMR, Chennai 119.

Dr. K. Arun Vasantha Geethan, School of Mechanical Engineering, St.Joseph's Institute of Technology, OMR, Chennai 119.

Harish Praveen, School of Mechanical Engineering, St.Joseph's Institute of Technology, OMR, Chennai 119

Gilbert, School of Mechanical Engineering, St.Joseph's Institute of Technology, OMR, Chennai 119.

(C) The Authors. Published by Blue Eyes Intelligence Engineering and Sciences Publication (BEIESP). This is an open access article under the CC BY-NC-ND license (http://creativecommons.org/licenses/by-nc-nd/4.0/)
Biodiesel has become an attractive for environmental benefits such as non-toxic and eco-friendly and these are made from the renewable resources. Biodiesel contains large amount of oxygen content. This leads to complete combustion. Due to this fact the emission of carbon monoxide and hydrocarbon is reduced. However, the emission of nitrogen oxides increased slightly compared to diesel. It also has other drawbacks such as higher viscosity, higher molecular weight, lesser heating value compared with diesel. These drawbacks cause poor atomization of fuel. Antioxidants play significant role in emission characteristics as well as performance characteristics.

Biodiesel can be derived from edible oil as well as nonedible oil. The use of edible oils for biodiesel production may lead to self-sufficiency problem in vegetable production. It is considered to be the better alternative for diesel fuel in standard diesel engine. This is because biodiesel possess almost similar properties as diesel. Also the use of biodiesel does not require a major modification in the engine construction. In that view, biodiesel which is renewable form of energy is derived from vegetable oil or animal fat based oil has drawn a lot of attention among researchers. The use of non-edible oil is significant because edible oil is necessary for food. Also the biodiesel production from edible vegetable oil is considered to be expensive. In this experimental study, the biodiesel is produced from pongamia oil which is non-edible vegetable oil. This experimental investigation is to conducted in two stages. The second stage is the same analysis is to be carried by adding nano additive copper oxide in the above mentioned fuels. From this the best combination is found out and test is again carried out by adding an oxidation inhibitor. The objective of this study is to find the best fuel among the above combination to achieve better performance and reduced emissions.

These have led researchers to focus on renewable source of energy for reducing the reliance on fossil fuels. Also the petroleum products lead to severe environmental problems such as air pollution and global warming. This study aims to reduce the emission of nitrogen oxide by adding an oxidation inhibitor Tert-Butylhydroquinone (TBHQ).Therefore in this study the analysis is to be carried by adding nano additive copper oxide for about $50 \mathrm{ppm}$ in the above mentioned fuels. From this the best combination is found out and test is again carried out by adding the oxidation inhibitor. 


\section{MATERIALS AND METHODS}

Table 1 Properties of Pongamia methyl ester and diesel

\begin{tabular}{|c|c|c|}
\hline Properties & Diesel & $\begin{array}{c}\text { Pongamia methyl } \\
\text { ester (B20) }\end{array}$ \\
\hline $\begin{array}{c}\text { Kinematic viscosity at } \\
40^{\circ} \mathrm{C}\end{array}$ & 4.3 & 3.45 \\
\hline Density & 831 & 723 \\
\hline Caloricity & 40,226 & $36,356 \mathrm{KJ} / \mathrm{kg}$ \\
\hline Flaring point ${ }^{\circ} \mathrm{C}$ & 59 & 63 \\
\hline Ignition point ${ }^{\circ} \mathrm{C}$ & 64 & 67 \\
\hline Carbon residue & 0.28 & 0.35 \\
\hline
\end{tabular}

\section{EQUIPMENT SETUP}

The experiment was conducted in single cylinder four stroke diesel engine. The encumbrance at which the fuel is injected was about 200 bars. The detailed information about the engine is presented in the Fig 2.1. Eddy current dynamometer is used to put on fluctuating loads. AVL Di gas 444 analyzer was used to measure the emission of hydrocarbon, carbon monoxide and nitrogen oxides.

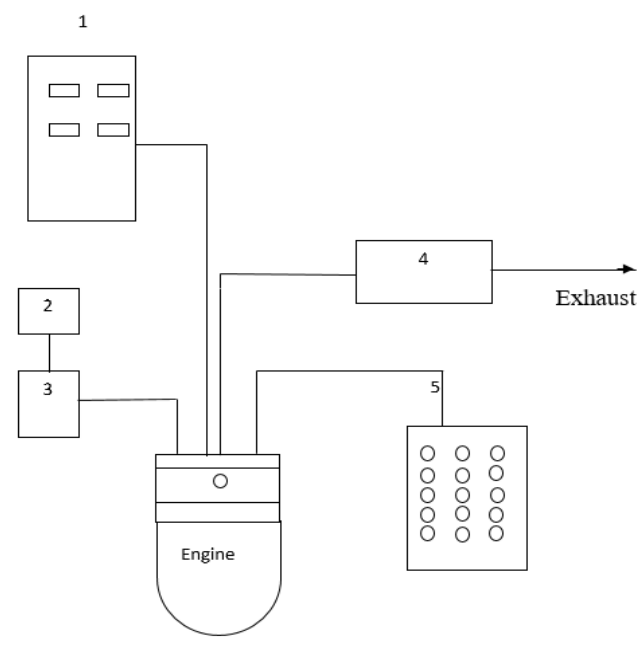
1. Control panel
2. Fuel tank
3. Fuel flow meter
4. AVL Digas 444 analyser
5. Electrical loading using DC generator

Fig 2.(a) Equipment setup

\section{RESULTS AND DISCUSSIONS}

\subsection{Comparison Of Thermal Efficiency}

The brake thermal efficiency for all fuel samples is shown in Fig 5.1. It is witnessed that the productivity has been escalated by $13.36 \%$ for biodiesel blend with TBHQ and adding Copper oxide (B20+CuO+TBHQ) on comparison with biodiesel blend (B20) and for the diesel with $\mathrm{CuO}$ the brake thermal efficiency is increased by $12.35 \%$ on comparison with pure diesel. Then the values are compared between $\mathrm{B} 20$ with $\mathrm{CuO}$ and diesel with $\mathrm{CuO}$, it is perceived that the productivity has been boosted by $24.67 \%$ for B20 with $\mathrm{CuO}$ on comparison with diesel with $\mathrm{CuO}$.

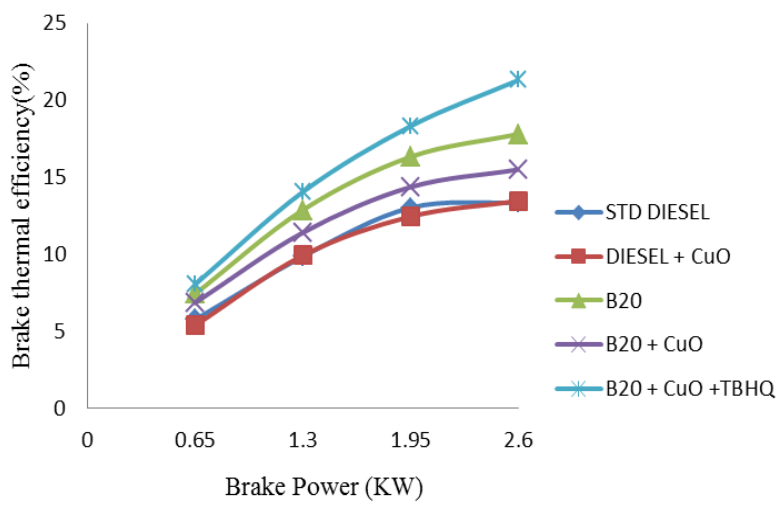

Fig 3.(a) Comparison of Brake thermal efficiency

\subsection{Comparison Of Fuel Intake}

The brake specific fuel consumption for all fuel samples can be inferred from Fig 5.2. It is witnessed that the brake specific fuel consumption has been decreased by $2.63 \%$ for biodiesel blend with TBHQ and adding Copper oxide (B20+CuO) on comparison with biodiesel blend (B20) and for the diesel with $\mathrm{CuO}$ the brake specific fuel consumption is increased by $1.425 \%$ on comparison with pure diesel. Then the values are compared between B20 with $\mathrm{CuO}$ and diesel with $\mathrm{CuO}$, it is observed that the brake specific fuel consumption is increased by $5.83 \%$ for $\mathrm{B} 20$ with $\mathrm{CuO}$ as additive on comparison with diesel with $\mathrm{CuO}$.

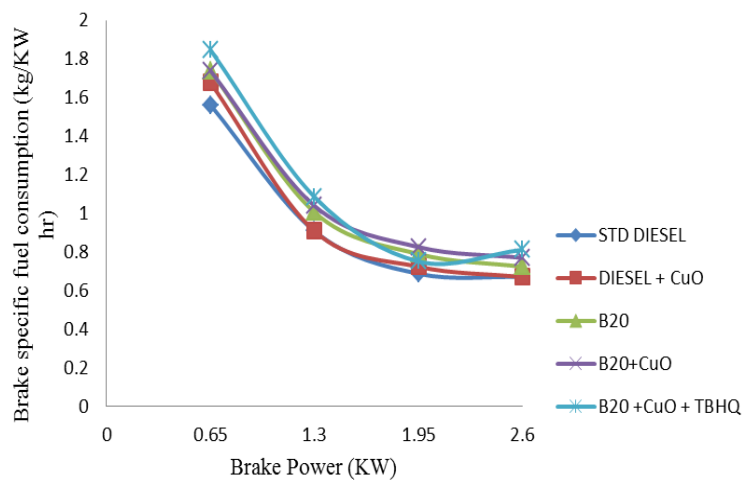

Fig 3.(b) Variation of Fuel intake

\subsection{Hydrocarbon Discharge}

It is witnessed from the fig. 3(c) that the hydrocarbon emission is increased by $44.7 \%$ for biodiesel blend with TBHQ and adding Copper oxide (B20+CuO+TBHQ) on comparison with biodiesel blend (B20) and for the diesel with $\mathrm{CuO}$ the hydrocarbon emission is decreased by $41.6 \%$ on comparison with pure diesel. HC emission slightly increased by $6.2 \%$ for B20 on comparing with pure diesel. This increase is due to the addition of antioxidant because antioxidant will reduce oxygen content in fuel thereby the $\mathrm{HC}$ emission is increased. Hydrocarbon emission decreases when there is high oxygen content in fuel.

Published By: 


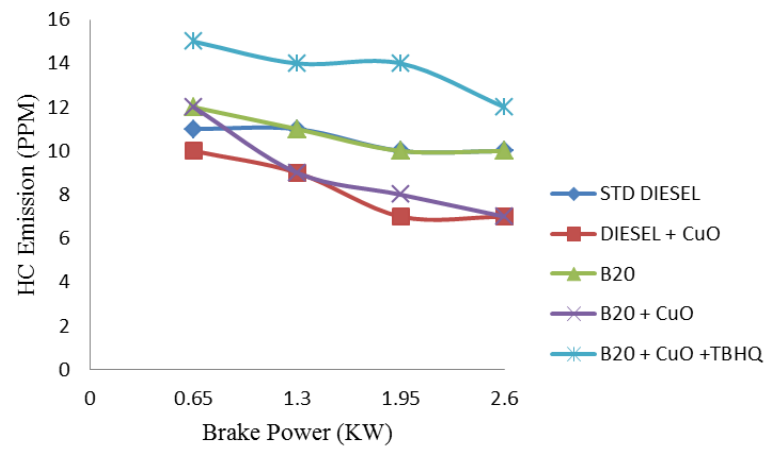

Fig 3.(c) Comparison of emission of hydrocarbon

\subsection{Carbon Monoxide Discharge}

It is observed from the fig 3.(d) that the carbon monoxide emission is increased by $42.04 \%$ for biodiesel blend with TBHQ and adding Copper oxide (B20+CuO+TBHQ) on comparison with biodiesel blend (B20) and for the diesel with $\mathrm{CuO}$ the carbon monoxide emission is increased by $19.86 \%$ on comparison with pure diesel. This increase is due to the addition of antioxidant because antioxidant will reduce oxygen content in fuel thereby the $\mathrm{CO}$ emission is increased. Carbon monoxide emission decreases when there is high oxygen content in fuel.

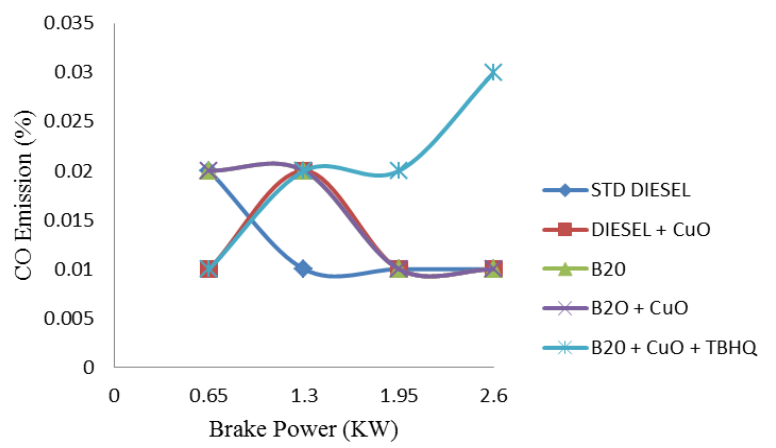

Fig 3.(d) Variation of CO Discharge

\subsection{Nitrogen Oxide Discharge}

It is witnessed from the fig 3.(e) that the nitrogen oxide emission is decreased by $23.73 \%$ for biodiesel blend with TBHQ and adding Copper oxide (B20+CuO+TBHQ) on comparison with biodiesel blend (B20) and for the diesel with $\mathrm{CuO}$ the nitrogen oxide emission is increased by $14.1 \%$ on comparison with pure diesel. Then the values are compared between $\mathrm{B} 20$ with $\mathrm{CuO}$ and diesel with $\mathrm{CuO}$, it is observed that the NOx emission is increased by $23.31 \%$ for B20 with $\mathrm{CuO}$ as additive on comparison with diesel with $\mathrm{CuO}$. The emission reduces because of the addition of antioxidant TBHQ.

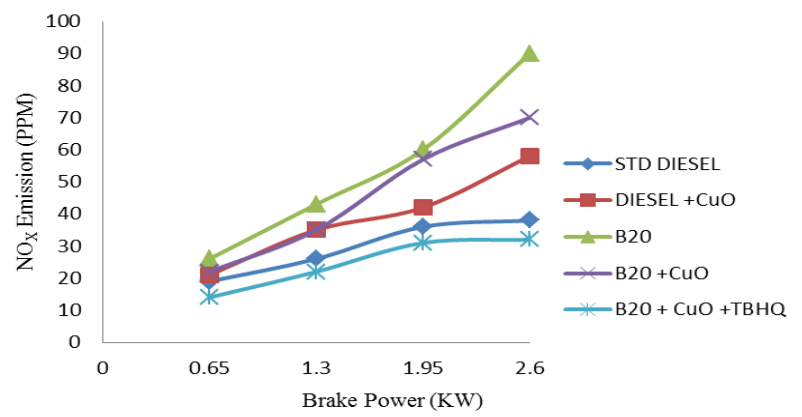

Fig 3.(e) Comparison of emission of nitrogen oxide

\section{CONCLUSION}

The subsequent points are the inferences that we obtained from this experiment

- $\quad$ The energy conversion (thermal to mechanical) has been escalated for B20 blend with TBHQ and adding Copper oxide (B20 + $\mathrm{CuO}+\mathrm{TBHQ})$ sample on comparison with diesel.

- Brake specific fuel consumption increases slightly for all samples on comparison with pure diesel.

- Emission of HC and CO increases slightly in its value for the B20 blend with TBHQ and adding Copper oxide (B20 + CuO +TBHQ) on comparing with B20 and pure diesel.

- Emission of NOx decreases for B20 blend with TBHQ and adding Copper oxide (B20 + CuO + TBHQ) on comparing with B20 and pure diesel.

- NOx emission decreases as the result of addition of antioxidant.

Considering all the above points, B20 blend with TBHQ and adding Copper oxide (B20 + $\mathrm{CuO}+\mathrm{TBHQ})$ fuel sample have higher brake thermal efficiency and lower NOx emission with slight increase in brake specific fuel consumption and slight increase in emission of $\mathrm{HC}$ and $\mathrm{CO}$ value

\section{REFERENCES}

1. P.Sabarish Kumar, S.Ashwin Kannan, A.Sathish Kumar, K.Arun Vasantha Geethan, "Impact of Oxidation Inhibitors on Performance and Emission Characteristics of a Low Heat Rejection Diesel Engine", International Journal of Vehicle Structures \& Systems, 2016.

2. P.Sabarish Kumar, K.Karuppasamy, A.M.B.Rakheeb Basha, A.P.Vetrivel, "Optimization of injection timing in a low heat rejection engine with Pongamia Methyl Ester, International Journal of Applied Engineering Research, 2015

3. Gopinathan Thilasi, Arulshri Kandampalayam Ponnusamy, Rajasekar Rathanasamy, Sathish Kumar Palaniappan, Sabarish Kumar Palanisamy, "Reduction of Harmful Nitrogen oxide Emission from Low Heat Rejection Diesel Engine using Carbon Nano Tubes", Thermal Science, 2016

4. S.Jaichandar, K.Annamalai and P.Arikaran, 2014. "Comparative evaluation of pongamia biodiesel with open combustion chambers in a DI Diesel Engine”. International Journal of Automotive Engineering and Technologies.

5. P.Sabarish Kumar, K.Arun Vasantha Geethan, K.Shanmuga Priyan, B.Vijay, "Impact of antioxidant on performance and emission characteristics of diesel engine", International Journal of Pure and Applied Mathematics, 2017.

6. M.V. Mallikarjun, G. Lakshmi Narayana Rao and Venkata Ramesh Mamilla, 2013. "Effect of Engine Fuelled with Jatropha Methyl Esters Blends with Diesel", Procedia Engineering.

7. Mohd Hafizil Mat Yasin, Rizalman Mamat, Ahmad Fitri, Yusop, Rafidah Rahim, Amir Aziz, Liyana Amer Shah, 2013. "Fuel physica characteristics of biodiesel blend fuels with alcohol as additives" Procedia Engineering.

8. P.Sabarish Kumar, K.Karuppasamy, A.M.B.Rakheeb Basha, A.P.Vetrivel, Experimental Investigation of a Low Heat Rejection Diesel Engine with Pongamia Methyl Ester, International Journal of Applied Engineering Research, 2015

9. Rolvin D'Silva, Mohammed Hafeez, Joyal Fernandez, Faheem Paloth, Ibrahim Abdul Rahiz, K.G. Binu, K. Raju and Thirumaleshwara Bhat, 2017. 'Effect of Copper oxide Nano additives on the Performance and Emissions Characteristics of a C.I. Engine' Energy and Power, 7(4): 99-104.

10. M. Vijay kumar, A. Veeresh Babu, P. Ravi kumar, 2016. "The impacts on combustion, performance and emissions of biodiesel by using additives in direct injection diesel engine" - Alexandria engineering journal. 


\section{Performance Analysis of Diesel Engine using Copper Oxide Nano Additive}

\section{AUTHORS PROFILE}

P. Sabarish Kumar, currently working as Assistant Professor at St.Joseph's Institute of Technology, obtained his B.E. degree in Mechanical Engineering in the year 2012 from Kongu Engineering College, Erode, M.E. degree in Thermal Engineering in the year 2015 from Regional Centre of Anna University, Tirunelveli. Currently pursuing Ph.D. degree in SRM University, Chennai. He has published 6 Scopus Indexed journals.

D. Arthur Jebastine Sunderraj, currently working as Assistant Professor at St.Joseph's Institute of Technology, obtained his B.E. degree in Mechanical Engineering in the year 2009 from Francis Xavier Engine, Tiruneleveli, M.E. degree in Production Engineering in the year 2013 from National Engineering College, Kovilpatti Currently pursuing Parttime Ph.D. degree in Anna University, Chennai. He has published 4 Scopus Indexed journals.

Dr. K. Arun Vasantha Geethan, Professor and Head of Mechanical Department, obtained his M.E degree in CAD / CAM in the year 2004 from Govt. College of Engineering, Tirunelveli and got his Ph.D., from Sathyabama University, Chennai. 